\title{
Coaches' Transformational Leadership Behavior and its Effect on Team Cohesion as Perceived by Female Football Players in Jordan
}

\author{
Ziad L. AlTahayneh \\ Professor of Sport Management \\ Department of Coaching and Sport Management \\ Faculty of Physical Education and Sport Sciences \\ Hashemite University \\ Zarqa, Jordan \\ Haya. M. Qatami \\ Fulltime Lecturer \\ Faculty of Physical Education and Sport Sciences \\ Hashemite University \\ Zarqa, Jordan
}

\begin{abstract}
The main purpose of this study was to investigate the influence of transformational leadership behaviors on team cohesion as perceived by female football players in Jordan. Sixty-one football players were surveyed using a translated version of the Multifactor Leadership Questionnaire (Avolio \& Bass, 2004) and Team Cohesion Questionnaire (Allawi, 1998). The results indicated that football players perceived their coaches to display high levels of transformational leadership. They also reported high levels of team cohesion. In addition, the results showed a positive relationship between coaches' leadership behaviors and team cohesion. Perceived leadership behaviors of idealized influence and intellectual stimulation were significant predictors of team cohesion and accounted for $22 \%$ of the variance in team cohesion.
\end{abstract}

Keywords: transformational leadership, cohesion, football, coaching, sports performance

\section{Introduction}

Leadership has probably been written about, formally researched, and informally discussed than any other topic (Luthans, 2011). Many theories and frameworks have been developed in the last few decades, but certainly the most widelyresearched is the theory of transformational leadership. Transformational leadership, as its name implies, is a process that changes and transforms individuals.It is a form of leadership that elevates the beliefs and motives of others, and supports them in achieving higher levels of functioning (Avolio, 1999). It involves an exceptional form of influence that moves followers to accomplish more than what is usually expected of them(Northouse, 2004, p. 169). Transformational leadership has been conceptualized as containing four separate components, or characteristics denoted as the (4 I's) of transformational leadership (Bass, 1985, 1990; Bass \& Avolio, 1994, 1997, Avolio \& Bass, 2004; Bass \& Riggio, 2006). These factors include idealized influence, inspirational motivation, individualized consideration, and intellectual stimulation. Idealized influence refers to charismatic actions in which leaders become role models who are admired, respected, and emulated by followers. Inspirational motivation refers to leaders with a strong vision to the future based on values and ideals. A leader who communicate high expectations, inspire and energize others to go beyond minimally accepted standards. Individualized Consideration is defined as considering the followers' individual needs and developing their individual strengths. Finally, intellectual stimulation involves engaging the rationality of others, encouraging them to approach old situations in new ways, and empowering them to contribute new ideas and develop innovative strategies (Avolio \& Bass, 2004; Bass \& Riggio, 2006). The extensive research in the past years has proved the effectiveness of transformational leadership in all contexts (Morton et al., 2011). Likewise, research in physical education and sport contexts has also shown that transformational leadership is positively associated with a wide variety of individual and organizational outcomes (e.g., AlTahayneh, \& Wezermes, 2008; AlTahayneh, Khasawneh, \& Abed Al-hafiz, 2009; Kao\& Tsai, 2016; Stenling \& Tafvelin, 2014; Wang \& Hu, 2017). 
One variable that has received much attention in many domains, including sports, is team (or group) cohesion, which is defined as "a dynamic process that is reflected in the tendency for a group to stick together and remain united in the pursuit of its instrumental objectives and/or for the satisfaction of member affective needs" (Carron, Brawley, \& Widmeyer, 1998, p. 213). This definition highlights the nature of cohesiveness as it is manifested in most groups, including sport teams, work groups, and social and friendship groups (Carron et al., 1998).

The interest in team cohesion stems, in part, from the belief that cohesion plays an important role in team performance, a belief that has been largely supported in the Western culture (Shields, Gardner, Bredemeier, \& Bostro, 1997). Research has demonstrated statistical associations between coaches' leadership styles and cohesion at individual and team levels. For example,Parazak (2011) reviewed this association, and found that transformational leadership predicted increased team cohesion. Female athletes rated their teams as more cohesive than did male athletes at Division-I, Division-II, and Division-III institutions sponsored by the NCAA. Huang (2003) and Heydarinejad and Adman (2010) suggested a significant relationship between coaching behaviorsand team cohesion.

Kim and Cruz (2016) found a statistically significant positive correlation between coaching behavior and cohesion in general. In addition, both task and social cohesion were positively correlated with coaching behavior; although the magnitude of the relationship was larger for task cohesion than for social cohesion, the difference was negligible.

Miles (2014) found that leaders who are perceived as utilizing a broad range of leadership behaviors have a greater effect on overall team performance and perceived team cohesion than those who are perceived as employing only one style. Moreover, the results from the same group of examined leaders found a positive and strong relationship between perceptions of team cohesion and team performance. As mentioned above, a great amount of research has been conducted to explore the relationship between coaches' leadership behaviors and team cohesion. This research was greatly drawn on Western ideas and measurements (Wendt, Euwema, \& Hetty van Emmerik, 2009). According to Yukl (2013), a large amount of the research on leadership during the past half century has been mainly conducted in the United States, Canada, and Western Europe and minimal research have been conducted in non-western cultures.

The dearth of research studies about leadership effects on team cohesion in non-western cultures, especially in the Middle East and Arab countries encouraged the conduct of this study. According to Leong and Fischer (2010), research must go beyond the U.S. and European contexts if we intend to develop a universal model of transformational leadership. Therefore, the current study aims to contribute to the existing literature by exploring the relationship between transformational leadership behaviors of football coaches and team cohesion as perceived by female football players in Jordan.

Specifically this study tries to answer the following questions:

1- What are the football players' perceptions of the coaches' transformational leadership behaviors?

2- What is the level of football players' team cohesion?

3- Isthere a relationshipbetween coaches'transformational leadership behaviors and team cohesion?

2. Methodology

\subsection{Participants}

This study applied a purposive sampling method to recruit participants. Sixty-one female football players representing the different age groups in the national football team of Jordan participated in this study. Of the respondents, $21(34.43 \%)$ players were with the first national team, 19 players $(31.14 \%)$ were with under-19 team, and 21 players were with under-16 team. The participants age ranged from 14 to 30 years with a mean of 18.15 years $(\mathrm{SD}=4.575)$. In addition, the majority of the participants $(60.65 \%)$ reported that they had play experience of less than 4 years, $(24.60 \%)$ had $4-8$ years of play experience, and $14.75 \%$ had more than 8 years of play experience with the national team.

\subsection{Measures}

\subsubsection{Measurement of leadership}

A translated version of the Multifactor Leadership Questionnaire (MLQ Form 5X-Short; Avolio \& Bass, 2004) was used to assess coaches' leadership behaviors. Al-Momani and AlTahayneh (2007) translated the MLQ from English to Arabic using translation back translation technique. 
In the current study, only 20 items measuring transformational leadership subscales (i.e., idealized influence, intellectual stimulation, individualized consideration, and inspirational motivation) were used.The MLQ uses a five-point Likert-type scale with responses ranging from 0(not at all), 1(once in a while), 2(sometimes), 3(fairly often), to 4(frequently, if not always). Scores for eachsubscale were obtained by summing the values and dividing by the number of items in that subscale.

The MLQ-5X has strong validity and reliability and has been usedextensively in research worldwide. In Arab countries, validity and reliability for the MLQ have been demonstrated throughdifferent studies (e.g., Al-Momani \&AlTahayneh, 2007; AlTahayneh\& Wezermes, 2008; AlTahayneh, et. al, 2009). For example, AlTahaynehand Wezermes (2008) reported internal consistency estimates (Cronbach's alpha) of 0.85 for Inspirational Motivation, 0.86 for Individualized Consideration, and 0.87 for Idealized Influence, and Intellectual Stimulation.

\subsubsection{Measurement of Cohesion}

Team Cohesion Questionnaire (TCQ) developed by Allawi (1998) was used to measure perceived cohesion. The TCQ consists of 12 items. Participants responded to each item on a 9-point Likert scale, ranging from 1(strongly disagree) to 9(strongly agree). In order to assess overall team cohesion, all the individual item responses were summed and then divided by the number of items. Higher scores represent stronger perceptions of cohesiveness among team members. The TCQ proved to be a valid and reliable instrument to measure team cohesion. Construct and criterion-related validity were demonstrated, and internal consistency was good with a Cronbach alpha of 0.78 (Allawi, 1998).

\subsection{Data analyses}

Statistical analysis was conducted using the Statistical Package of SocialSciences (SPSS) version 20 software. Data were analyzed descriptivelyto determine the transformational leadership style of the coach, team cohesion, and the basic characteristics of the participants. Stepwise regression analysis was conducted to determine the effects of the four independent variables of transformational leadership, as predictors of team cohesion. Additionally, the internal consistency of the instruments used in this study was determined by calculating Cronbach alpha coefficients

\subsection{Procedure}

One of researchers, who works with the Jordan Football Association, contacted the players and invited them to participate in this study. All participants received an introductory letter and an informed consent agreement that explained the purpose of this study. Once the consent agreement was signed and collected, the researchers scheduled an appointment to meet with the players. At the meeting, which took place before practice and at team meetings, the players were given an oral explanation of the study and were emphasized that participation was based on voluntary consent. The researches assured the participants that their responses would remain confidential and their identities anonymous.Players who agreed to participate were asked to fill the MLQ and TCQ and returned them directly to the researchers.

\section{Results}

To identify the coaches' transformational leadership behaviors as perceived by the football players, means and standard deviations were computed. The results are presented in Table 1. As shown in the table, the means of coaches' transformational leadership ranged from 3.03 to 3.20 with a total mean of 3.11. Since the lowest possible score on the MLQ is 0 (no transformational leadership) and the maximum score is 4, a reported mean of 3.11 provide evidence of the existence of transformational leadership among football coaches in Jordan. 
Table 1.Means and standard deviations of coaches' transformational leadership behaviors as perceived by the football players

\begin{tabular}{lll}
\hline Transformational Leadership Subscales & Mean & Standard Deviation \\
\hline Idealized influence & 3.20 & .362 \\
Intellectual stimulation & 3.15 & .394 \\
Inspirational motivation & 3.07 & .395 \\
Individualized consideration & 3.03 & .472 \\
Total & 3.11 & .356 \\
\hline
\end{tabular}

Table 2 presents the means and standard deviations of the total team cohesion. As shown in the table, the level of team cohesion was high with a total mean of (6.968) and a standard deviation of.943.

Table 2. Means and standard deviations of team cohesion

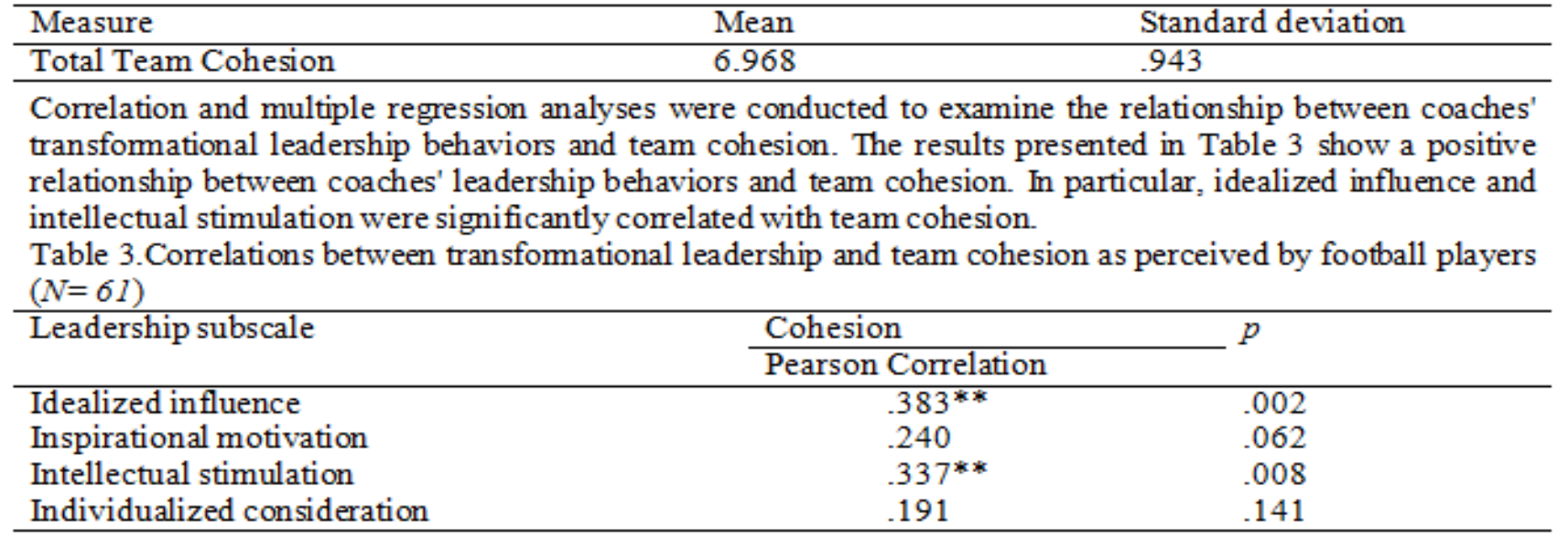

The results of the stepwise regression presented in Table 4 and Table 5 indicated that idealized influence and intellectual stimulation were significant predictors of team cohesion and explained $22 \%$ of the variance $\left(\mathrm{R}^{2}=.22\right.$, $\left.\mathrm{F}_{(2,58)}=8.176, \mathrm{p}<.001\right)$. Examination of the standardized regression coefficients $(\beta$ 's) revealed that that idealized influence was the main significant predictor of team cohesion $(\beta=.331, \mathrm{p}<.01)$ and accounted for $14.6 \%$ of the variance in team cohesion followed by intellectual stimulation which accounted for $7.4 \%$ of the variance $(\beta=.276$, $\mathrm{p}<.05$ ). The other two leadership behaviors (i.e., intellectual stimulation and individualized consideration) were not significant predictors of team cohesion and failed to add any accounted variance in the regression equation.

Table 4.Stepwise regression with transformational leadership (idealized influence, inspirational motivation, intellectual stimulation, individualized consideration) as predictors and team cohesion as criterion

\begin{tabular}{|c|c|c|c|c|c|c|c|}
\hline Model & $\mathrm{R}$ & $\mathrm{R}^{2}$ & Adjusted $\mathrm{R}^{2}$ & $\begin{array}{l}\mathrm{R}^{2} \\
\text { Change }\end{array}$ & $\begin{array}{l}\mathrm{F} \\
\text { Change }\end{array}$ & $\begin{array}{l}\text { Overall } \\
\mathrm{F}\end{array}$ & $p$ \\
\hline 1 & $.383^{\mathrm{a}}$ & .146 & .132 & .146 & $10.123^{* *}$ & 8.176 & .001 \\
\hline$\overline{2}$ & $.469^{\mathrm{b}}$ & .220 & .193 & .073 & $5.464^{*}$ & & \\
\hline
\end{tabular}

a. Predictors: (Constant), idealized influence

b. Predictors: (Constant), idealized influence, intellectual stimulation

c. Dependent Variable: cohesion

Table 5.Standardized and Unstandardized Coefficients

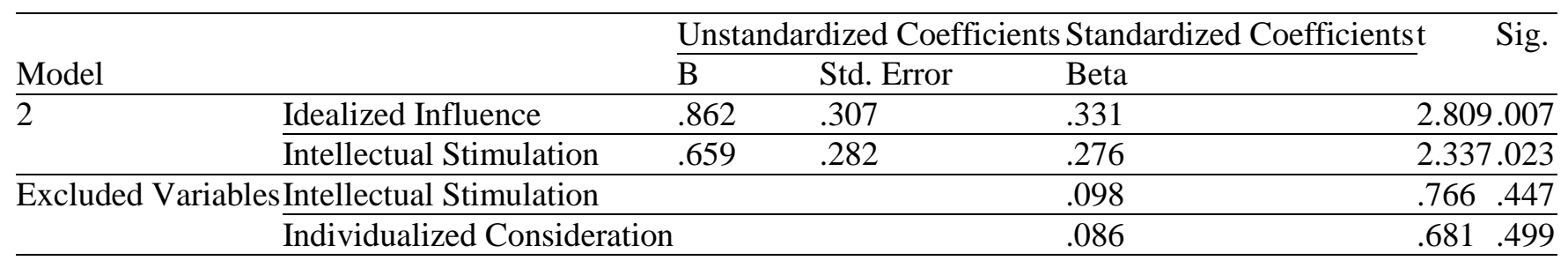




\section{Discussion}

The current study had three purposes: (1) to examine the football players' perceptions of the coaches' transformational leadership behaviors; (2) to examine the level of team cohesion; and (3) to explore the relationship between coaches' transformational leadership behaviors and team cohesion? The results confirmed the presence of transformational leadership among football coaches in Jordan. This also provides further support for the universality of the transformational leadership theory. The players perceived their coaches to exhibit high levels of transformational behaviors in all dimensions of transformational leadership. The means of coaches' transformational leadership ranged from 3.03 to 3.20 with a total mean of 3.11 (see Table 1). The researchvalidated benchmark for transformational leadership is more than three (Bass \& Avolio, 2011). It seems obvious that football players appreciate such a behavior exhibited by their coaches to improve their abilities and performance.

This is consistent with the findings from previous research which identified the effectiveness of transformational leadership in a variety of contexts including sports (e.g., Al-Momani \& AlTahayneh, 2007; AlTahayneh \& Wezermes, 2008; AlTahayneh, et al., 2009; Callow, Smith, Hardy, Arthur, \& Hardy, 2009; Coleman, 2012; Cronin, Arthur, Hardy, \& Callow, 2015; Parazak, 2011; Price \& Weiss, 2013; Stenling \& Tafvelin, 2014).

Regarding team cohesion, the players reported high levels of team cohesion. This result is consistent with previous research, which indicate that high levels of group cohesion are considered advantageous and are associated with enhanced performance (Asamoah, \& Grobbelaar, 2017). Mach, Dolan, and Tzafrir (2010) reported, "Highly cohesive groups tend to be more united and committed to success than groups with little cohesion" (p. 775). Smith, Arthur, Hardy, Callow, \& Williams (2013) believed that group cohesion contributes to good team performance. In their view, highly cohesive teams are likely to work together more effectively and perform better than less cohesive teams (Smith et al., 2013).

With respect to the relationship between transformational leadership and team cohesion, the results showed that transformational leadership was positively correlated to team cohesion, indicating that the more a coach shows a transformational leadership behavior, the higher the cohesion is. A possible explanation for this relationship is that coaches who are perceived to exhibit transformational leadership behaviors provide a sense of the value of membership, teamwork, and commitment. These variables in turn increased players' perceptions of cohesion on their team. This result is in line with the findings of previous research mentioning that transformational leadership is related to team cohesion in sport contexts (e.g., Callow, et al., 2009; Cronin, et al., 2015; Price \& Weiss, 2013; Smith, et al., 2013; Stenling \& Tafvelin, 2014). For example, Stenling and Tafvelin (2014) stated that transformational leadership is effective in not only enhancing athlete motivation and performance, but also in increasing team cohesion. Asmawi, Zakaria, and Wei (2013) also stated that transformational leadership is appropriate when the leader aims to provide directions, energy, and cohesion for individuals with diverse knowledge and abilities.

The regression analysis demonstrated unique contributions of transformational leadership to the variance in team cohesion. Specifically, two factors of transformational leadership (i.e. idealized influence and intellectual stimulation) made significant contributions to the variance of team cohesion. These factors accounted for $22 \%$ of the variance explained in team cohesion. Team coaches who exhibit idealized influence behavior, which represents the charismatic aspect of transformational leadership (Bass \& Avolio, 1994), and are able to provide intellectual stimulation by encouraging team members to question their own practices and ways of completing tasks (Jung \& Sosik, 2002), will positively affect cohesion levels and make the team a more cohesive unit.

\section{Limitations of The Study}

Despite the fact that this study did find a significant relationship between coaches' transformational leadership and team cohesion and contributed to the existing literature on transformational leadership in sports, there are some limitations that should be noted. First, the target population and sample were selected using a convenience sampling method. Therefore, the generalizability of the findings is limited and generalizations should not be made to other populations or sports. Second, this study involved only female football players from the national team of Jordan, which limited the generalizability of the results beyond the sport of football to other sports. Third, the responses of the participants were collected at one point of time using self-reported measures. These responses are often inflated and subjected to social desirability bias (Jung \& Sosik, 2002). In the current study, we tried to reduce the effect of social desirability by having an anonymous study. 
A final limitation is the correlational nature of this study, which means that causality cannot be established between variables. Experimental and longitudinal research designs are warranted to address this limitation.

\section{Recommendations For Future Research}

The recommendations for further study include the following: First of all a similar study could be conducted with more participants and with different age groups and male athletes. Together with this, a longitudinal research is essential to explore changes in the cohesion-performance relationship over time, as well as the factors that contributing to them. Future research could also investigate cohesion in other types of individual and team sports so that there is a larger data pool that might increase generalizability of findings. Finally, it is recommended that further qualitative research be conducted in order to gain a deeper understanding of how leadership behaviors affect team cohesion in different sports.

\section{References}

Allawi, M. H. (1998). Al-ekhtibarat alnafseya lelriyadeyeen [Psychological tests for athletes]. Cairo, Egypt: Book Center for Publishing.

Al-Momani, Z. \& AlTahayneh, Z. (2007). Perceived transformational leadership style of physical education deans at colleges of physical education and its relation to faculty job satisfaction. Abhath Al-Yarmouk: Humanities \& Social Sciences Series, 23(2), 643-665.

AlTahayneh, Z. L., Khasawneh, A., \& Abed Al-hafiz, A. (2009). Perceived transformational leadership behavior of soccer coaches and its relation to players' satisfactionat Arab universities. Abhath Al-Yarmouk: Humanities \& Social Sciences, 25(3), 609-622.

AlTahayneh, Z. L., \& Wezermes, I. (2008).The relationship between transformational leadership and organizational culture in colleges of physical education in Jordan. Journal of Educational and Psychological Sciences, 9(1), 35-59.

Asamoah, B. \& Grobbelaar, H. W. (2017). Team cohesion and performance during a university soccer championship: Two sides of the coin. South African Journal for Research in Sport, Physical Education and Recreation, 39(1), 1-15.

Asmawi, A., Zakaria, S., \& Wei, C. C. (2013). Understanding transformational leadership and R\&D culture in Malaysian universities. Innovation, 15(3), 287-304. DOI: 10.5172/impp.2013.15.3.287

Avolio, B.J. (1999). Full leadership development: Building the vital forces in organizations. Thousand Oaks, CA: Sage.

Avolio, B. J., \& Bass, B. M. (2004). Multifactor Leadership Questionnaire. Manual and Sampler Set (3rd ed.). Redwood City, CA: Mindgarden. http://dx.doi.org/10.1207/s1532754xjprr1602_2

Bass, B. M. (1985). Leadership and performance beyond expectations. New York: Free Press.

Bass, B. M., (1990). Bass and Stogdill's handbook of leadership: Theory, research managerial applications $\left(3^{\text {rd }}\right.$ ed.). New York: Free Press.

Bass, B. M., \& Avolio, B. (1994). Improving organizational effectiveness through transformational leadership. Thousand Oaks, CA: Sage Publications.

Bass, B. M., \& Avolio, B. J. (1997). Full range leadership development: Manual for the multifactor leadership questionnaire. Redwood City, CA: Mind Garden Inc.

Bass, B. M. \& Avolio, B. J. (2011). Multifactor Leadership Questionnaire: Feedback report. Redwood City: Mind Garden Inc.

Bass, B. M., \& Riggio, R. E. (2006). Transformational leadership (2nd ed.). Mahwah, NJ: Erlbaum.

Callow, N., Smith, M. J., Hardy, L., Arthur, C.A. \& Hardy, J. (2009). Measurement of transformational leadership and its relationship with team cohesion and performance level. Journal of Applied Sport Psychology, 21(4), 395-412, DOI: 10.1080/10413200903204754

Carron, A.V., Brawley, L.R. \& Widmeyer, W.N. (1998).The measurement of cohesiveness in sport groups. In J. L. Duda (Ed.), Advances in sport and exercise psychology measurement (pp.213-226). Morgantown, WV: Fitness Information Technology.

Coleman, J. (2012). A functional model of team leadership for sport. Doctoral Dissertation, Florida State University, USA. Retrieved from

https://diginole.lib.fsu.edu/islandora/object/fsu:182810/datastream/PDF/view 
Cronin, L. D., Arthur, C.A., Hardy, J., \& Callow, N. (2015). Transformational leadership and task cohesion in sport: The mediating role of inside sacrifice. Journal of Sport and Exercise Psychology, 37(1), 23-36. https://doi.org/10.1123/jsep.2014-0116

Heydarinejad, S. \& Adman, O. (2010). Relationship between coaching leadership styles and team cohesion in football teams of the Iranian university league. Studies in Physical Culture and Tourism, 17(4), 367-372.

Huang, J. (2003). The effects of perceived coach leadership behavior upon team cohesion and performance for Taiwanese college basketball teams. Unpublished doctoral dissertation, United States Sports Academy, Daphne, Alabama, USA.

Jung, D. I. \& Sosik, J. J. (2002). Transformational leadership in work groups: The role of empowerment, cohesiveness, and collective-efficacy on perceived group performance. Small Group Research, 33(3), 313-336. https://doi.org/10.1177/10496402033003002

Kao, S. \& Tsai, C. (2016). Transformational leadership and athlete satisfaction: The mediating role of coaching competency. Journal of Applied Sport Psychology, 28(4), 469-482. https://doi.org/10.1080/10413200.2016.1187685

Kim, H. \& Cruz, A. B. (2016). The influence of coaches' leadership styles on athletes' satisfaction and team cohesion: A meta-analytic approach. International Journal of Sports Science \& Coaching, 11(6), 900909. DOI: $10.1177 / 1747954116676117$

Leong, L. Y. \& Fischer, R. (2010). Is transformational leadership universal? A meta-analytical investigation of multifactor leadership questionnaire means across cultures. Journal of Leadership \& Organizational Studies, 18(2), 164-174. https://doi.org/10.1177/1548051810385003

Luthans, F. (2011). Organizational behavior: An evidence-based approach(12th ed.). New York, NY: McGrawHill/Irwin.

Mach, M., Dolan, S., \& Tzafrir, S. (2010). The differential effect of team members' trust on team performance: The mediation role of team cohesion. Journal of Occupational and Organizational Psychology, 83(3), 771-794. https://doi.org/10.1348/096317909X473903

Miles, A. (2014). An examination of the relationship between perceived leadership behaviors, perceived team cohesion and team performance. (Doctoral dissertation, Kennesaw State University, Georgia, USA). Retrieved from: http://digitalcommons.kennesaw.edu/cgi/viewcontent.cgi?article=1658\&context=etd

Morton, K. L., Barling, J., Rhodes, R. E., Mâsse, L. C., Zumbo, B. D. \& Beauchamp, M. R. (2011). The application of transformational leadership theory to parenting: Questionnaire development and implications for adolescent self-regulatory efficacy and life satisfaction. Journal of Sport \& Exercise Psychology, 33, 688-709.

Northouse, P. G. (2004). Leadership theory and practice (3rd ed.). Thousand Oaks, CA: Sage Publications.

Parazak, S. E. (2011). Transformational leadership in sport: Coaching behaviors, team cohesion, and studentathlete commitment. (B.A. thesis), Rhodes College, Memphis, Tennessee, USA.

Price, M. S. \& Weiss, M. R. (2013). Relationships among coach leadership, peer leadership, and adolescent athletes' psychosocial and team outcomes: A test of transformational leadership theory. Journal of Applied Sport Psychology, 25(2), 265-279. DOI: 10.1080/10413200.2012.725703

Shields, D. L., Gardner, D. E., Bredemeier, B. J., \& Bostro, A. (1997). The relationship between leadership behaviors and group cohesion in team sports. The Journal of Psychology, 131(2), 196-210. DOI: 10.1080/00223989709601964

Smith, M. J., Arthur, C. A., Hardy, J., Callow, N., \& Williams, D. (2013). Transformational leadership and task cohesion in sport: The mediating role of intrateam communication. Psychology of Sport and Exercise, 14(2), 249-257. https://doi.org/10.1016/j.psychsport.2012.10.002

Stenling, A. \& Tafvelin, S. (2014). Transformational leadership and well-being in sports: The mediating role of need satisfaction. Journal of Applied Sport Psychology, 26(2), 182-196. https://doi.org/10.1080/10413200.2013.819392

Wang, Y. \& Hu, T. (2017).Transformational leadership behavior and turnover intention in China physical education. EURASIA Journal of Mathematics Science and Technology Education, 13(9), 6357-6368. DOI: 10.12973/eurasia.2017.01070a

Wendt, H., Euwema, M. C., \& Hetty van Emmerik, I. J. (2009). Leadership and team cohesiveness across cultures. The Leadership Quarterly, 20(3), 358-370. https://doi.org/10.1016/j.leaqua.2009.03.005

Yukl, G. (2013). Leadership in organizations (8th ed.). New York: Pearson Education Inc. 